\title{
Quality of cesarean section nursing care and its reflection up-on women's satisfaction with labor experience
}

\author{
Inaam H. Abdelati ${ }^{1 *}$, Om Hashim M. Saadoon², Amal Roshdi Ahmed Mostafa ${ }^{3}$ \\ ${ }^{1}$ Assist.Prof. of Maternity Obstetrics, \&Gynecological Nursing, Faculty of Nursing, Port said University, Egypt \\ ${ }^{2}$ Lecturer of woman's Health\& Midwifery Nursing, Faculty of Nursing, Mansoura University, Egypt \\ ${ }^{3}$ Lecturer of Maternal and Neonatal Health Nursing, Faculty of Nursing, Beni-Suef University, Egypt \\ *Corresponding author E-mail:gogo_na100@yahoo.com
}

\begin{abstract}
Women satisfaction is a crucial predictor for maintaining and monitoring the quality of health care and can inform service development and delivery.Aim: To evaluate the quality of cesarean nursing care at hospital of Mansura University, the outcomes of it preserve advanceandsupportqualityof care and womensatisfaction. By using a descriptive design the study conducted at obstetrics and gynecology department in Mansoura university hospital. On a total of 200 women had undergoingelective cesarean section operation. Data collection by, structured interviewed questionnaire, observationchecklist and satisfactionassessment scale. Results; Findings indicated that most of studied women had received a complete care during intraoperative \& immediate post-operative $92.5 \%$ \& $95.0 \%$ respectively. Meanwhile, $80.0 \%$ \& $62.5 \%$ of them didn't received health education and emotional support also , the higher percentage of studied women were satisfied with general environment, cleanliness, communication and physical care 75.0\%, 75.0\%, 65.0\% and 58.0\% respectively. While, $60.0 \%$ of them were dissatisfied with continuity of care. Regarding involving in decision making, all of studied sample $100 \%$ were dissatisfied. Finally there was a positive association of quality of CS nursing care with the level of women's satisfaction with ( $p=<0.05)$.Conclusion: The current study indicated that, there are several factors that affected on women's satisfaction. higher percentages of them were satisfied with general environment, cleanliness, communication and physical care and dissatisfied with psychological care, continuity of care and involvement in decision making. There was a highly statistically associationof women's satisfaction with CS nursing care offered. Recommendation: Woman satisfaction is an imperative health care outcome its assessment is recommended tobe a part of hospital quality ofcare monitoring and improvement programs.
\end{abstract}

Keywords:Caesarean Section; Quality; Women Satisfaction.

\section{Introduction}

The improvement of maternity care is a key health policy focus, in recognition that health and wellbeing have implications throughout life and motherplaysakey role in family wellbeing. Official birth rates increase but associated complicationsand death rates have been slow in reduction. One strategy to improve mother heath and decreases complication by providing quality of nursing carethat refers to "doing the right thing, at the right time, in the right way, for the right patient and having the best possible results". Itis one of the key challenges facing maternal and neonatal services as deprived care fromqualityduringbirths is mainfactor of complications (Henke, et 2018; Bui, et al2018).

The experience of labor is a complex, many dimensional and subjective event. It's relatedto outcomes of well-baby, as well as the physical and cognitive processes experienced by individual woman. As yielded by literature Caesarean Section (CS) is one of the commonest abdominal surgery there has been a dramatic increment rate around the world, which presently surpasses $30 \%$.In Egypt, cesarean birth rate has been raised drastically from 27.6, to 70\%(Martischang, et al 2018.;Martin, 2016;Al-Rifai, \& Aziz, 2018).

Quality of CS nursing care are outlined have common dimensions of comprehensive womencare plus women objectives and desires around surgery. It includes preoperative fasting and bowel planning, early oral intake, restricting utilize of drains and catheters, multimodal analgesia, early ambulation, and prioritizing eu-volemia and normo-thermia. (Tarin et al., 2014; Thiele et al, 2015). Among the most crucialdimensions of quality iscommunication with women, responsiveness, provision of patient education, (World Health Organization2018).

There is an agreement that quality services necessitatesknowledgeable educated staffs who providesproper appropriate carerespectfully and in well-preparedclinics. Nurses should know the purpose and physiologic impact of their actions during CS care on clients,and be able to evaluate women's responses to those actions. In addition meeting women informational needs, promoting women relaxation, and providing emotionalsupport. The nursing assessments and interventions begin preoperative and continue through the labor and postoperative. In addition, any departure from the normal should be promptly documented and reported. All the aforementioned points have a remarkable influence on women's treatment process, improvement, and satisfaction (Rahman, , Rahim, , \&Arif, (2017). 
Satisfaction is a concept contains a attitude and response to an experience plus cognitive assessment of the emotional response. It represents a balance between woman perception of the expected nursing care and received. If the received care exceeds expectations, the woman is highly satisfied or delighted. It is the most frequently reported outcome measures for quality of care and monitoring of healthcare services (Varghese \&Rajagopal., 2013). In addition, literature asserts, recognition of client's dissatisfaction is a valid, costeffective method to improve the quality of care. So, the assessment of women's satisfaction and perceptions of labor experience are an important indicatorto women themselves, organization, haveimplicationonwell-being of the mother, the mother-infant relationship,staffsforproviding the best services forlaboring mother(Alidosti et al.,2013;Naghizadeh et al.,2014).

\section{Significance of study}

The birth of a childnormally or by cesarean is one of the most important and unforgettable experiences in a woman's life. Ithas long-term effects on their physical and psychosocial well-being, Therefore, it is essential that nurses providing quality ofcare understand its refection on maternal satisfaction (Hall, et al 2018). Womansatisfaction with nursing servicesis very importance, dueto the nature of nursing skills and practice, women may judge the quality of hospital upon it(Karimi, \&Moghadam, 2017)Limited narrow studies have investigated maternal satisfaction with the quality ofnursing practices for caesarean section at hospitals.Sowe aim to determine the quality of CS care and mothers.

\section{AIM}

Todetermine women's satisfaction level for elective CS based on the quality of nursing care offered. Specific Objectives:

- Evaluate the quality of nursing care offered for cs.

- Assess women's satisfaction regarding pre, intra as well as postoperative care.

- Determine factors that may affect on woman's satisfaction.

- Identify the relation between quality of care offered for cs and women's satisfaction.

\section{Material and methods}

This research was quantitative, descriptive on 200 participantswhounderwentelectiveCSin the obstetrics and gynecology department at Mansoura University Hospital affiliated to Mansourauniversity at Dakahlia governorate. Itwas chosen for availability and accessibility of the women from all over Dakahlia Governorate, particularly from Mansoura city and all nearby areas; provides low cost health services compared with other private centers and clinics. Sample size was chosen according to Schlesselman, 1982 assayequation. Where: $-\mathrm{N}=$ Sample size $, \mathrm{P}=(\mathrm{P} 1+\mathrm{P} 2) / 2, \mathrm{Q}=1-\mathrm{P}, \mathrm{Z} \mathrm{Q}=1.96$, and $\mathrm{Z} \mathrm{B}=0.84$

$\mathrm{N}=\frac{2 \mathrm{Pq}(\mathrm{ZQ} 12+\mathrm{ZB}) 2}{(\mathrm{P} 1+\mathrm{P} 2) 2}$

A purposive sample technique sampling was used. Mothers who did not have any recognized history of medical and mental diseases, gestational age from 37 weeks to 42 weeks and those who undergo elective cesarean section. Also, agree to participate on the study. For data collection, a questionnaire was used included three parts; the firstis demographic data and obstetric and the 2 ndis CS nursing care observation checklist woman was individually observed by the researcher using a 61-items checklist to collect data on intrapartum care, it was included 9 parts: Hospital Admission Procedures ( 7 items):such as receiving the woman and agreement, identification, preparing the woman for examination and taking the sample for analysis, Following of infection control practices (6 items) by health care providers, Emotional Support during the labor (5 items) to woman from nurses, Recording and reporting of information (5 items): It was used to assess the recording of all information related to mother's condition and reporting the results of all examinations, Nursing care preoperative(11 items): such as assessment the, giving I.V fluids and drugs, measuring vital signs, fetal heart monitoring,..etc.Nursing care intraoperative (5 items):It was related to nursing care which performed during the deliveryof the baby, Nursing care immediate post CS ( 5 items): it was related to nursing care),Nursing care post-operative (11 items): It was related to nursing care performed after 2 hours CS and Giving health teaching (6 statements): about the importance of breast feeding, breast care, self-care, warning signs during pripreum, immunization schedule and appropriate time for using family planning methods. Scoringsystem. The care items observed to be completely done were scored"3", the items observed incompletely done were scored "2" and the items not be done were scored "1". Complete: mean the care offered was according to standardized care. Incomplete: missing some items of the standardized care. Not done: this means less than $25 \%$ of care is given or not given at all.

Assessment of women's satisfaction regards CS with 38 points mentioned by Rajeswar, (2011) then this part was modified by the researchers, and it contains a list of 38 statements that relate to the nursing care received by woman during CSandthis questionnaire was provided with questions based on a Likert scale of 1 to 3 (Satisfied), (Uncertain) and (Unsatisfied) options implying the level of satisfaction about nursing care offered for cs7care domains. surrounding environment (6 items related to operatingroom calmness, lighting, temperature, smell, crowdedness and arrangement.), cleanliness (4 items cleanliness of rooms, beds, clothes and bathroom.), communication(10items related to explanation of the things clearly, talking with the mother; as well as nurse's attentiveness, patience, kindness, calmness, support, encouragement, respect and reassurance),physical care (5items) related to relief of pains, meeting woman's needs, care of the baby, frequency of examination and length of stay in the operating rooms.),care maintenance (4 items related to the presence of nurse nearly to woman for answering her questions, providing continual care and responding to woman's needs quickly.),psychological care ( 4 items related to maintaining adequate privacy during examinations and procedures, time of accessibility to her baby after delivery and time of breast feeding initiation (bonding).), patient approval in procedures (5items related to woman's freedom to move about and to be in any position she likes, as well as making decision about drugs, anesthesia, nursing procedures and pain relief methods.).Scoring system: Every statement was given a score; satisfied was scored (3), uncertain was scored (2) and unsatisfied was scored (1). Range of response from 38-114. Total women satisfaction score will conducted according to total women response on the sheet. If the women total score from 77- 114 was considered satisfied. If the women total score at the level of 76 so their stratification will be judged as uncertain. If the total women scored 75 or less was considered dissatisfied. 
The questionnaires were reviewed by 5 expertise's of from nursing and medical staff to judge content validity, and reliabilityby alpha Cronbach coefficient $=0.9$ The pilot study doneon $10 \%$ of the study subjects that represents 20 women andexcluded from sample. Based on findings of the pilot study, certain modifications on the tools were done.

All ethical issues were followedin all of the study phases: an anonymity and confidentiality of the subjects weremaintained. The researcher introduced herself to the women and briefly explained the nature and objective and women were assured that the study maneuver will cause no actual or potential harm to her. Also, they were assured that professional help will be provided for her whenever needed. Women were also assured that the information obtained during the study will be confidential and used for the research purpose only. An official lettersent to the director of the hospital to conduct the study after explaining and clarifying the aim of the study. The analyst attended the inpatient unit from 8,00 pm till 5, $00 \mathrm{PM}$. four times per week this was repeated until the sample size achieved. Interviewing was carried out for each subject upon admission to the inpatient unit. The researcher introduced her to the mothers and explains the aim of the study in a simple way before teaching. The researcher started the interview, which lasted about 20 minutes. The study was carried out during the period from June2017 to March 2018. Mothers were followed -up by the researcher until discharge.

\section{Handling and analysis of data}

All statistical analysis were done by SPSS for version 20.0. Descriptive statistics including frequency, distribution were used to describe different characteristics. Univariate analyses including Chi-Square test was used to test the significance of results of quantitative variables and Spearman. Rho correlation coefficient ( $\mathrm{r}$ test). The significance of the results was at less than 5.

\section{Results}

The research includes 200 mothers the more than halfof them $(53 \%)$ were 30 to $<40$ years old. The majority (83\%) werehousewives, only $15 \%$ had high education, and $70 \%$ were receiving antenatal care at government hospitals. (55\%) of them monthly income insufficient.The mean gestational age was more than 37 weeks andunderwent CS in the morning time(Table 1).

Table (2) indicates that the majority of studied women received a complete care during intraoperative nursing care\& immediate postoperative nursing care $92.5 \%$ \& $95.0 \%$ respectively. The higher percentage of them had received a complete care which related to recording and reporting and hospital admission procedures $57.5 \%$ \& $65.0 \%$ respectively. Meanwhile, regarding nursing care postoperative two thirdof studied sample had received incomplete care $(60.0 \%)$. Finally, $80.0 \% \& 62.5 \%$ of them didn't received health education and emotional support respectively.

Table (3) indicated that, the higher percentage of studied women were satisfied with general environment, cleanliness, communication and physical care $75.0 \%, 75.0 \%, 65.0 \%$ and $58.0 \%$ respectively. While, $60.0 \%$ \& $15.0 \%$ of them were respond uncertain and dissatisfied respectively with continuity of care. Moreover, $45.0 \%$ and $20.0 \%$ of women were dissatisfied and uncertain respectively with psychological care. Regarding involving in decision making, all of studied sample were dissatisfied.

Fig (1): women satisfaction level regarding CS care. It showsthat $52.5 \%$ of studied sample were satisfied while $46.5 \%$ of studied sample were unsatisfied .only $1 \%$ of them were uncertain.

Table (4) illustrate that, women with age group from 30 to $<40$ years were highly significant satisfied $(61.9 \%$, $\mathrm{p}=<0.001)$, living in urban $(50.5 \%)$, had university education $(0.9 \%, \mathrm{p}=<0.001)$, not working $(76.3 \%)$, and receiving care in Governmental hospital $(74.3 \%$, $\mathrm{p}=0.004)$. while there are non-statistically significant differences between the residence, occupation, and income with level of satisfaction.

Table (5) reveals a highly statistically significance concerning women's satisfaction level and number of parity and history of caesarean section $\left(\mathrm{P}=0.005^{*}\right)$, Also, number of gravida, number of abortion and gestational age with women's satisfaction level $(\mathrm{p}<0.05)$.

Table (6) shows that, there was a highly statistically significance between all items of women's satisfaction and quality C S nursing care offered.

Table (7) shows a positive association between quality of CS care with the level of women's satisfaction.

Table 1: Distribution of the Studied Sample According to General Characteristics $(\mathrm{N}=200)$

\begin{tabular}{|c|c|c|}
\hline General Characteristics & No. & $\%$ \\
\hline \multicolumn{3}{|l|}{ Age by year } \\
\hline $20<30$ & 52 & 26 \\
\hline $30<40$ & 106 & 53 \\
\hline$\overline{M e a n} \pm \mathrm{SD}$ & $33.9 \pm 6.7$ & \\
\hline \multicolumn{3}{|l|}{ Residence } \\
\hline Rural & 90 & 45 \\
\hline Urban & 110 & 55 \\
\hline \multicolumn{3}{|l|}{ Educational status } \\
\hline Illiterate & 27 & 13.5 \\
\hline Primary & 25 & 12.5 \\
\hline Preparatory & 118 & 59 \\
\hline University & 30 & 15 \\
\hline \multicolumn{3}{|l|}{ Occupational status } \\
\hline Working & 34 & 17 \\
\hline Not working & 166 & 83 \\
\hline \multicolumn{3}{|l|}{ Place of health care } \\
\hline Government hospital & 140 & 70 \\
\hline Private & 21 & 10.5 \\
\hline \multicolumn{3}{|l|}{ Cost of treatment } \\
\hline Free & 93 & 46.5 \\
\hline Health insurance & 55 & 27.5 \\
\hline Private & 52 & 26 \\
\hline \multicolumn{3}{|l|}{ Income sufficient } \\
\hline Yes & 90 & 45 \\
\hline
\end{tabular}


Table 2: Nursing Careduring CS Stage in Different Aspects as Observed by the Researcher $(\mathrm{N}=200)$

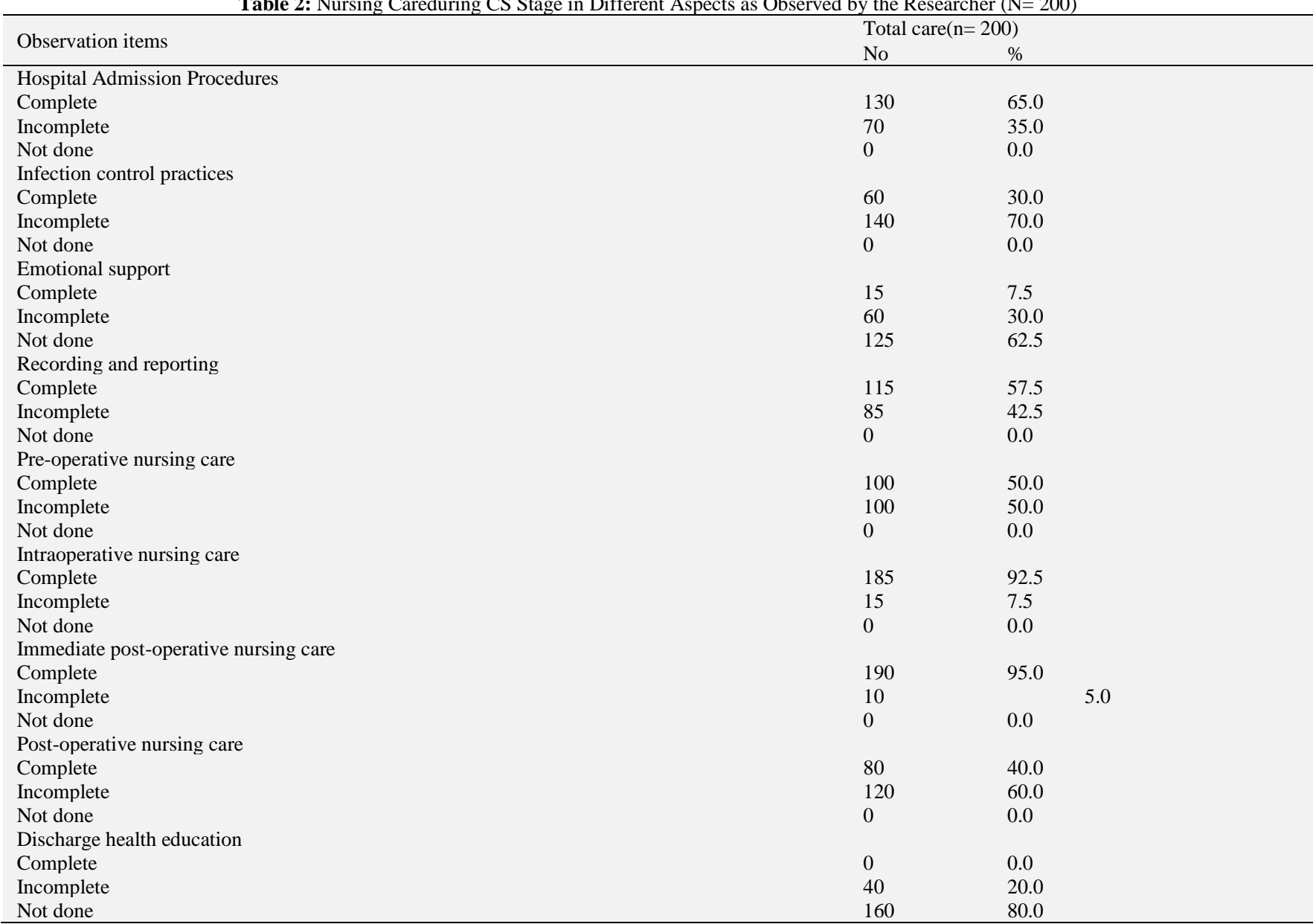

Table 3:Satisfaction Rates Among Studied Sample in Different Aspects $(\mathrm{N}=200)$

\begin{tabular}{|c|c|c|}
\hline Satisfaction items & No $(200)$ & $\%$ \\
\hline \multicolumn{3}{|c|}{ General environment } \\
\hline Satisfied & 150 & 75.0 \\
\hline Uncertain & 16 & 8.0 \\
\hline \multicolumn{3}{|l|}{ Cleanliness } \\
\hline Satisfied & 150 & 75.0 \\
\hline Uncertain & 16 & 8.0 \\
\hline Dissatisfied & 34 & 17.0 \\
\hline Satisfied & 130 & 65.0 \\
\hline Uncertain & 20 & 10.0 \\
\hline Dissatisfied & 50 & 25.0 \\
\hline \multicolumn{3}{|l|}{ Physical care } \\
\hline Satisfied & 116 & 58.0 \\
\hline Uncertain & 34 & 17.0 \\
\hline Dissatisfied & 50 & 25.0 \\
\hline \multicolumn{3}{|l|}{ Continuity of care } \\
\hline Uncertain & 120 & 60.0 \\
\hline Dissatisfied & 30 & 15.0 \\
\hline \multicolumn{3}{|l|}{ Psychological care } \\
\hline Satisfied & 70 & 35.0 \\
\hline Uncertain & 40 & 20.0 \\
\hline Dissatisfied & 90 & 45.0 \\
\hline \multicolumn{3}{|c|}{ Involving in decision making } \\
\hline Satisfied & 0 & 0.0 \\
\hline Uncertain & 0 & 0.0 \\
\hline Dissatisfied & 200 & 100.0 \\
\hline
\end{tabular}




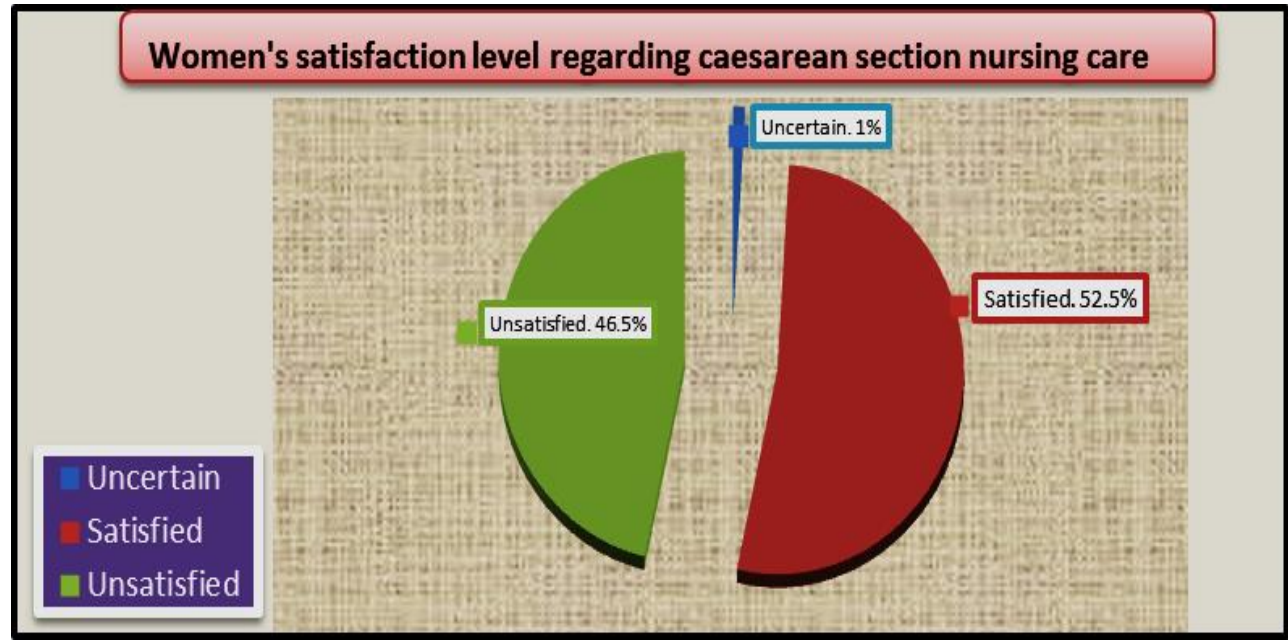

Fig. 1: Women Satisfaction Level Regarding CS Care.

Table 4:Relation between Women's Satisfaction Level and Socio-Demographic Characteristics of the Studied Women

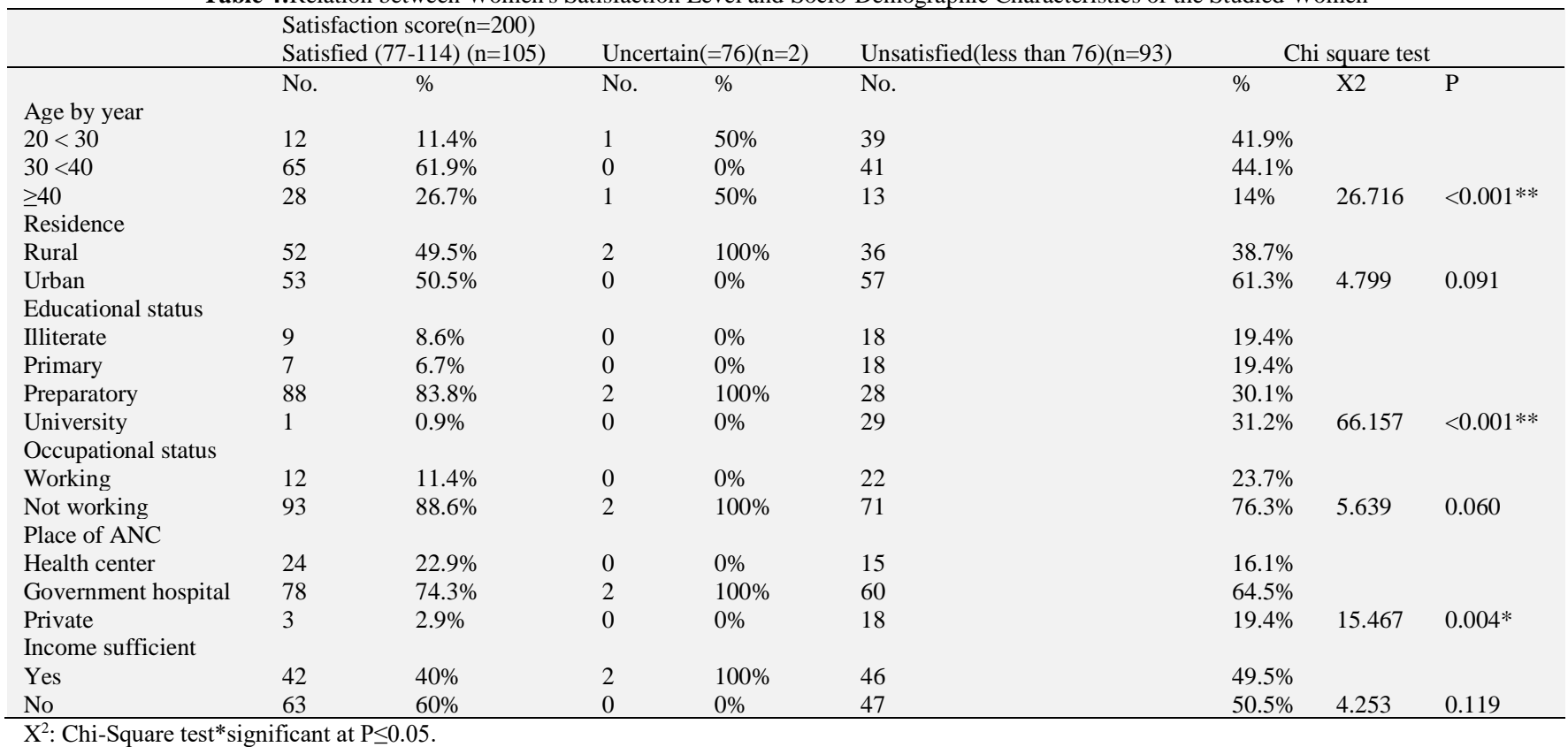

Table 5: Relation between Women's Satisfaction Level and Obstetric History of the Studied Women (N=200)

\begin{tabular}{|c|c|c|c|c|c|c|c|}
\hline \multirow{3}{*}{ Items } & \multicolumn{6}{|c|}{ Satisfaction score } & \multirow{3}{*}{ Significance } \\
\hline & \multicolumn{2}{|c|}{ Satisfactory(77-114) $(n=105)$} & \multicolumn{2}{|c|}{$\operatorname{Uncertain}(=76)(\mathrm{n}=2)$} & \multicolumn{2}{|c|}{ Unsatisfactory(less than 76$)(\mathrm{n}=93)$} & \\
\hline & No. & $\%$ & No. & $\%$ & No. & $\%$ & \\
\hline \multicolumn{8}{|l|}{ Gravidity } \\
\hline One & 3 & 2.9 & 2 & 100 & 2 & 2.1 & \multirow{3}{*}{$\mathrm{X}^{2}=64.850 \mathrm{P}<0.001 * *$} \\
\hline Two & 74 & 70.4 & 0 & 0.0 & 47 & 50.5 & \\
\hline Three or more & 28 & 26.7 & 0 & 0.0 & 44 & 47.4 & \\
\hline \multicolumn{8}{|l|}{ Parity } \\
\hline One & 48 & 45.7 & 0 & 0.0 & 26 & 28.0 & \multirow[t]{3}{*}{$\mathrm{X}^{2}=65.912 \mathrm{P}<0.001 * *$} \\
\hline Two & 26 & 24.7 & 0 & 0.0 & 21 & 22.5 & \\
\hline Three or more & 28 & 26.7 & 0 & 0.0 & 44 & 47.4 & \\
\hline \multicolumn{8}{|l|}{ Abortion } \\
\hline None & 95 & 90.4 & 0 & 0.0 & 61 & 65.6 & \multirow[t]{2}{*}{$\mathrm{X}^{2}=24.960 \mathrm{P}<0.001 * *$} \\
\hline One or more & 10 & 9.6 & 2 & 100 & 32 & 34.4 & \\
\hline \multicolumn{8}{|c|}{ History of caesarean section } \\
\hline yes & 30 & 28.6 & 0 & 0.0 & 51 & 54.8 & $\mathrm{X}^{2}=15.496 \mathrm{P}<0.001 * *$ \\
\hline
\end{tabular}

$\mathrm{X}^{2}$ : Chi-Square test*significant at $\mathrm{P} \leq 0.05$.

Table 6: Correlation ofCS. Nursing Care with Women's Satisfaction Items for the Studied Women

\begin{tabular}{llc}
\hline Women's satisfaction items & \multicolumn{2}{c}{ Quality of intrapartum nursing care } \\
\hline & $\mathrm{r}$ & $\mathrm{p}$ \\
General environment & 0.690 & $<0.001^{* *}$ \\
Cleanliness & 0.438 & $<0.001^{* *}$ \\
Communication & 0.306 & $0.0001^{*}$ \\
physical care & 0.195 & $0.004^{*}$ \\
Continuity of care & 0.195 & $0.006^{*}$
\end{tabular}




$\begin{array}{lll}\text { Psychological care } & 0.238 & 0.0001 * \\ \text { Involving in decision making } & 0.239 & 0.002 *\end{array}$

*Statistical significant at p-value $<0.05 * *$ highly statistical significant at p-value $<0.001$.

Table 7:Associationofquality of CS Nursing Care with Women's Satisfaction Level

\begin{tabular}{lll} 
& Table 7:Associationofquality of CS Nursing Care with Women's Satisfaction Level & \\
\hline Women's' satisfaction level & quality of cs nursingcare & p-value \\
\hline & r & $0.0001^{*}$ \\
\hline
\end{tabular}

**Statistically Significance at $\mathrm{p} \leq 0.001$.

\section{Discussion}

Validating quality ofnursing care is the most key challenges fronting maternal services and women satisfaction with thisis a crucial parameter for assessing it. Maintaining and monitoring the quality of health care can result inservice development and improvement (Sehatyetal., 2016; Corso etal.,2016).The present study findings will behelpful if ittransformed into schedulesplans for improving the quality of health care system.

Concerning quality of CS nursing care the present study exposed that half of studied mothers had received incomplete care preoperative and perioperative. The current study finding in linewith the study of Changaee, et al (2014) in Iran about the quality assessment of perioperative CS care. Regarding the nursing care of postoperative, the current study indicated that, majorityof studied sample had received incomplete and below standard care which in the same line with(Lotto, 2015), who concluded that the quality of postnatal care presentedto clients was poor, below standard and nurses did not compliance withpredetermined guide-lines for managing postpartum mothers. Therefore,organization should emphasis on mothers need andproperassessmentand management during the first 24 hours afterCS to get most favorable outcomes.

Regarding nurses compliance with infection control measures onlyone third of infection control measures were done. This finding was supported by Mohamed, (2007) who reported the same result. This may be due to lack of nurses' knowledge, training programs or lack of resourcesand time. The current study findings were disagree with the study of Fashafsheh, et al. (2015) who studied performanceof nursing staff towards infection control measures in the Palestinian hospitals; they mentioned that, the common of the samplehad skillful practice of infection control.

Satisfaction with general environment is a considerable predictor of women's general satisfaction and experience of labor (Yuenyong, Obrien\&Jitapeet,2012) Regarding women's satisfaction level in relation to general environment and cleanliness, the study findings revealed that, the majority of mothers were satisfied with. The current study finding is agreed with Khumalo, (2014) \&Kavitha et al. (2014), who found that, the satisfaction levels among women was high with general environment. It may be due to emphasizing on cleanersto do their duties properly.

Evidence from our data explored a high level ofphysical care satisfaction but satisfactionwithcontinuity of care andpsychologicalsupportwere low. This is consistent with other studiesPerriman, \& Davis, (2016) found that, majority of women were satisfied with the physical care but not with its continuity .Generally these results may be due to the nurse left the woman for a long period of time particularly preoperative. The present study finding is disagree with the study of Dahlberg, \&Aune, (2013)inAustralia, which strongly indicated that the presence of a known midwife during labor helped women feel supported, Also, Kavitha et al. (2014) in Eritrea who assessed mother's satisfaction with intra-operative nursing care among mothers postnatal. They mentioned that, the majority of sample were highly satisfied regarding emotional and psychological support. Also, the study of Mbeinkong (2010) in Burea showed that mostof women reported attendance by the nurse at regular intervals and shoed their carness.

As regards involvingwomen in decision making, the results of this study illustrated all women dissatisfied. Involvement in decisions can affect women's perceptions of satisfaction. This result is disagree with the recent research of Lumadi, and Buch (2011) in South Africa, who mentioned that, one thirdof mothers were satisfied with the way in which they had been involved in decision making related to their care. Therapeutic communications significant themes that were identified as influencing client's satisfaction with care. It involves(listening, good manners, prompt relaxation, sympathy and smiling), caring behavior (caring to needs, acceptance of clients and sweet-talk) and interpersonal skills of nurses (self-assurance and competency)(Dzomeku, 2011).Nurses should emphasizing on communication skills and the manner of providing education to mother can elevating satisfaction. Concerning women's satisfaction with communication behaviors of nursing staff the current study findings showed slightly more than two thirds of studied sample was satisfied with nurses' communication. This result agreed with a study of Perriman, \& Davis, (2016).in Pakistan who show that about eighty of studied mothers were satisfied with communication factor. In this respect, Shafiei, et al. (2012) in Australia showed that the nature of interaction with nurses was mentioned by all women as particularly important in their satisfaction or dissatisfaction with the care they received during childbirth.

Our result is less thanstudy of Melese, et al (2014) whoshowedthathis studied sample were highly satisfaction with the health care providers communication.Bitew et al.,2015releaved that, more than $95 \%$ of reported that they were satisfied with communication withhealth care providers. Also, study of Amir, et al (2017) revealed that satisfaction with communication and explanations given were significanthigh. The current study findings were disagreed with Mohammed, et al(2014), who found in Jordan that, only $13.0 \%$ of women were satisfied with interpersonal communication. These differences in findings may be due to the difference in areas of the studies and the difference in population and their expectations and experiences.

This study revealed thatdissatisfaction of womenwithhealth education and given information post-operative. Thisin the same line with (Jagannathan\&, Tilak2008) who reported dissatisfaction with given information. Similarly, Azari et al .,2013 reported that post-operative educationwasnotsignificantlysatisfied with the care provided. In other studies byIzbizky et al., (2008)\&Nagizadeh(2009) satisfaction with health educationwas high. It could be due todifferent care systems. The low satisfaction rate could be explained by as the lack of time devoted to each patient as aresult of crowded hospitals in our country but we have todo our best.

In the light ofcurrent study there were a statistically significance between women's satisfaction level, their age, number of parityand previous CS. As observed the most of satisfied women were aged from $30<40$ years old and in para one. The current study findings are harmony with Jallowet al., (2012) who mentioned maternal general characteristics affected women's perceived of satisfaction with care. Maternal age and education were positively associated with satisfaction, Also Sehaty et al (2016) mentioned that there was significant association between satisfaction and woman's educational status. 
The current study findings are in disagree with recent study of Singla et al. (2015), who reported that, there is no statistically significant association between general characteristics (age, education, socio-economic class) and level of satisfaction. Moreover, Mohammed (2015) found that, there is no significant relation between general characteristics (age, and occupation) and level of women' satisfaction. The current study findings are in contrast with Mohammed (2015), who found a relation between general characteristics (education, and residency) and level of satisfaction. Furthermore, Younas, \&Sundus, (2018,).reported that, there is no statistically significant relation between general characteristics (age, family income, and gender) and level of satisfaction.Moreover,Melese, etal (2014)who revealed that studies from low- and middle-income countries showed that there is advanced satisfaction rates amongst those who can pay more for health organization (Bitew etal.,2015; Srivastavaetal ., 2015;Corso et 2017).The possible explanation that the study setting provides low and high cost health service for women so satisfied women got aspecial paid care.The difference in the finding between the past and recent studies may be due to the difference in areas and times of these studies, difference in nature of people from country to another (their culture, social status and experiences). Also, this may be due to the difference in facilities of hospital, knowledge and practices of nursing staff.

Finally the current study findings revealed that, there was a statistically significance between women's satisfaction withquality of nursing care offered.Thisis in accordance with Azizi-et al(2012) who conducted a study to assess the relationship between nursing caring behaviors and patients' satisfaction in Iran. They observed a significant positive correlation of nursing caring behavior withpatient satisfaction. Also, the current study on the same line with the results of Akhtari et al. (2010), who noticed that, there was a positive association of patients' satisfaction with quality of care.On the other handthe current study findings are in contrast with Soliman, Kassam, and Ibrahim (2015), who found a negative associationof nurses' caring performance with patients' satisfaction.

\section{Conclusion}

Ourstudy revealed that majority of studied women had received a complete nursing care regardinghospital admission proceduresintraoperative \& immediate post-operative, recording and reporting. Meanwhile,the majority of them had received incomplete infection control practices and didn't receive emotional support nordischargehealth education.

The current study indicated that, there are several factors that affected on women's satisfaction. The higher percentages of studied women were satisfied with general environment, cleanliness, communication and physical care and dissatisfied with psychological care, continuity of care and involvement in decision making. There was a highly statistically significance between the level of women's' satisfaction with quality of CS nursing care offered.

\section{Recommendations}

- Woman satisfaction is an imperative health care outcome its assessment is recommended tobe a part of hospital quality ofcare monitoring and improvement programs.

- The hospital needs to organize training sessions for nurses derivedfrom the service quality assessmentand women satisfaction.

- Plan is necessary to develop the quality of health educationto get clients satisfaction.

- The mothersneeds health educationregardsphysical preparation on issues surrounding cesarean section, that can reduce distress and improve women's satisfaction with birth.

- Continuity of care, emotional support and involvement oflaboring women in decision making should be enhanced to improve their satisfaction.

- Woman satisfaction is an imperative health care outcome ,its assessment recommended to be a part and parcel of hospital quality of care monitoring and improvement programs

- further studies:

- Further studies must identify factors responsible for the low quality of nursing care offered for cs.

\section{References}

[1] Al-Rifai R., \& Aziz, F. (2018): An Apparent Lack in Level of Basic Knowledge of Caesarean section Delivery among Egyptian Females: Apopulation-Basedcross-Sectionalsurvey. Gynecolobstet, 8(463), 2161-0932.https://doi.org/10.4172/2161-0932.1000463.

[2] Amir H., Zewawi, N., \&Jaroudi, D. (2017): Involvement of Women with the Decision of Caesarean section And Their Degree of Satisfaction for Post-Operative Care and Painmanagement. J Women's Health Care. 6(403): 2167-0420.

[3] Azizi I., Sabdani A., Mousavi M., \&Hajbaghery M. (2012): Correlation Between Nurses’ Caring Behaviors and Patients' Satisfaction.Nurs Midwifery Stud. 1(1): 36-40.https://doi.org/10.5812/nms.7901.https://doi.org/10.5812/nms.7901.

[4] Bitew K., Yimam K., Ayichiluhm M. (2015): Maternal Satisfaction on Delivery Service and Its associated Factors among Mothers Who Gave Birth in Public Health Facilities Ofdebremarkos Town, Northwest Ethiopia. Biomed Res Int.; 2015:1-6https://doi.org/10.1155/2015/460767.

[5] Bui, H., Le, T., Pham, T., Doan, D., Nguyen, C., \& Duong, D. (2018): The Association between Gender inequalities and Women's Utilization of Maternal Health Services: A Cross-sectional Survey in Eight South Central Coast Provinces, Vietnam. Journal ofpublic Health Management and Practice, 24, S19-S27.https://doi.org/10.1097/PHH.0000000000000728.

[6] Changaee F., Irajpour M. Simbar A., \&Akbaris. (2014): Quality Assessment of per partumcare. Iranian Red Crescent Medical Journal, 16(6).https://doi.org/10.5812/ircmj.9069.

[7] -Corso E., BeeverD., Hind D., Fuller G., Wilson M., Wrench, I., \& Chambers D. (2017): Enhanced Recovery after Elective Caesarean: A Rapid Review Of Clinical Protocols, And An umbrella Review Of Systematic Reviews. Bmc Pregnancy and Childbirth, 17(1), 91.https://doi.org/10.1186/s12884-017-1265-0.

[8] Dahlberg U. \&\&Aune I. (2013): The Woman's Birth Experience-The Effect of Interpersonal relationships and Continuity of Care. Midwifery, 29(4), 407-415.https://doi.org/10.1016/j.midw.2012.09.006.

[9] Dzomeku, V. (2011): Maternal Satisfaction with Care duringLabor: A Case Study of Themampong-Ashanti District Hospital Maternity Unit in Ghana. International Journal of nursingand Midwifery, 3(3), 30-34

[10] Fashafsheh I., Eqtait, F., Ayeda, \&Harazneh L. (2015):Knowledgeand Practice of Nursing Staff towards Infection Control Measures inthe Palestinian Hospitals. Journal of education and Practice, 6(4), 79-90.https://doi.org/10.1186/2047-2994-4-S1-P270.

[11] Hall P., Foster J., Yount K., \& Jennings B. (2018): Keeping It Together and Falling Apart: Women's dynamic Experience of Birth. Midwifery, 58, 130-136.https://doi.org/10.1016/j.midw.2017.12.006. 
[12] Henke R., Karaca Z., Moore B., Cutler E., Liu H., Marder D., \& Wong H. (2018): Impact Of Health System affiliation On Hospital Resource Use Intensity And Quality Of Care. Health services Research, 53(1), 63-86.https://doi.org/10.1111/1475-6773.12631.

[13] Izbizky G., Minig L., Sebastiani M., \&Otaño L. (2008): The Effect of Early Versus Delayedpost caesarean Feeding on Women's Satisfaction: A RandomizedControlled trial. Bjog: An International Journal of Obstetrics \&Gynecology, 115(3), 332:338.https://doi.org/10.1111/j.14710528.2007.01591.x.

[14] Jagannathan M. (2008): Patient Satisfaction and Ethics ina Public Hospital Practice. Indian journalof Plastic Surgery. Official Publication ofthe Association of plastic Surgeons of India, 41(2), 107.https://doi.org/10.4103/0970-0358.44919.

[15] Jallow I., Chou Y., Liu, L., \& Huang N. (2012: Women's Perception of Antenatal Care Services Inpublic and Private Clinics in the Gambia. International Journal for Quality Inhealth Care, 24(6), 595-600.https://doi.org/10.1093/intqhc/mzs033.

[16] Karimi L. \&Moghadam N. (2017). Comparison of Coping Styles and Social Support among Patientsof Private and Public Hospitals. Int J Hosp Res, 6(1), 8-13.

[17] Kavitha P., Parasath, R., Solomonh., Tsegay L., Tsegay W., \&Teklit Y. (2014): Mother's Satisfaction With intrapartum Nursing Care Among Postnatal Mothers In OrottaNational referral Maternity Hospital, Asmara, Eritrea. International journal ofallied Medical Science and Clinical Research. 2(3):249-254.

[18] Khumalon. (2014): Factors That Influence Patients' Satisfaction With Peri-Partum Care Ingermiston Hospital Maternity Unit (Doctoral Dissertation). Faculty Of Health Science,UniversityofThe Witwatersrand Johannesburg.

[19] Lotto T. (2015): Assessment ofthe Quality of Postnatal Care Services (Doctoral dissertation, Mzumbe University).

[20] Lumadi T. \&Buch E. (2011): Patients' Satisfaction with Midwifery Services at A Regional Hospital and its Referring Clinics In The Limpopo Province Of South Africa. Africa Journal of Nursing and midwifery. 13 (2): 14-28.

[21] Martin (2016): The Sharing Economy: A Pathway To Sustainability Or A Nightmarish Form of Neoliberal Capitalism?. Ecological Economics, 121, 149-159.https://doi.org/10.1016/j.ecolecon.2015.11.027.

[22] Martischang R., Pires, D., Masson-Roy S., Saito, H., \&Pittet D. (2018): Promoting and Sustaining Ahistorical and Global Effort to Prevent Sepsis: The 2018 World Health Organization save Lives: Clean Your Hands Campaign.https://doi.org/10.1186/s13054-018-2011-3.

[23] Mbeinkong C. (2010): Patient Satisfaction With Intra-Partum And Postpartum Nursing Car: The Case of Buea Regional Hospital. Published Bachelor Dissertation In Nursing science, Faculty Of Health Sciences, Department Of Nursing, University ofbuea,and Republic Of Cameroon. July 2010.

[24] Mclellan J. \& Laidlaw A. (2013): Perceptions Of Postnatal Care: Factors Associated withprimiparous Mothers Perceptions Of Postnatal Communication And Care. Bmcpregnancy and Childbirth. 13(1):227.https://doi.org/10.1186/1471-2393-13-227.

[25] Melese T.,Gebrehiwot Y.,Bisetegne D., \& Habted.(2014):Assessment Of Client Satisfaction In Labor and Delivery Services At A Maternity Referral Hospital In Ethiopia Pan. AfrMedj. 17: 76.https://doi.org/10.11604/pamj.2014.17.76.3189.

[26] Mohammed A. (2015): Maternal Satisfaction Regarding Quality of Nursing Careduringlabor And Delivery In Sulaimani Teaching Hospital. InternationalJournalofNursing and Midwifery; 8(3): 18-27.

[27] Mohammed K., Shaban I., Homer C., \&Creedy D. (2014): Women's Satisfaction With Hospital-Based intrapartum Care: A Jordanian Study. International Journal of Nursing and midwifery, 6(3), 32-39.https://doi.org/10.5897/IJNM2014.0127.

[28] Naghizadeh S., Rezaie M., Sehhati F., Barzanje S., \&Ebrahimi H. (2014): Assessment mothers Satisfaction of Postpartum Care. Advances In Nursing \&Midwifery, 23(82), 71-78.

[29] Nagizadeh S. \&Sehati F. (2009): Assessment of Mothers' Satisfaction with the Care of maternal Care during Hospitalization for Labor and Delivery in Educational andnon-Educational Maternity Hospitals of Tabriz. Nurs Midwifery J Tabriz, 13, 29-36.

[30] Perriman N. \& Davis D. (2016): Measuring Maternal Satisfaction with Maternity Care: A systematic Integrative Review: What Is the Most Appropriate, Reliable and Valid tool That Can Be Used to Measure Maternal Satisfaction with Continuity of maternity Care? Women and Birth, 29(3), 293-299.https://doi.org/10.1016/j.wombi.2015.12.004.

[31] Powell-Jackson T., Morrison J., Tiwari S., Neupane B., \& Costello A. (2009): The Experiences Of Districts In implementing A National Incentive Programme To Promote Safe Delivery In Nepal. Bmchealth Services Research, 9(1), 97.https://doi.org/10.1186/1472-6963-9-97.

[32] Raeisi M., Alidosti M., \&Tahmasebi M. (2013): Evaluating the Women's Satisfaction of Hajarhospital Services after the Delivery. Journal of Clinical Nursing and midwifery. 2(1):1-8

[33] Rahman, M., Rahim N. \&Arif M. (2017): Barrier, Weakness and Utilization of Prepregnancyclinic Services. Archives of Public Health, 75(1), 67.https://doi.org/10.1186/s13690-017-0236-2.

[34] Rajeswari T. (2011): "A Study to Assess Patients Satisfaction with Quality of Nursing care. "Diplomadiss, Trivandrum.

[35] Schlesselman J. (1982): Optimal Allocation for the Comparison of Proportions. Biometrics 38, 1003-9https://doi.org/10.2307/2529880

[36] Sehaty F., Azari S., \&Ebrahimi H. (2016): Mothers Satisfied from Quality Of Care Given During cesarean Delivery In Public And Private Hospitals Of Tabriz, Iran. International journal of Women's Health and Reproduction Sciences. 4(4), 200204.https://doi.org/10.15296/ijwhr.2016.44.

[37] Singla N., Mamta, Taneja, A., \&Kaur J. (2015): Study on Satisfaction Regarding Intrapartum and postpartum Nursing Care among Women. International Journal of Current Research.7 (3): 13373-13375.

[38] Soliman H., Kassam A., \& Ibrahim, A. (2015): Correlation between Patients' Satisfaction and nurses' Caring Behaviors. J Biolagrichealth, 5(2), 30-41.

[39] Srivastava, A., Avan, B. I., Rajbangshi, P., \& Bhattacharyya, S. (2015): Determinants of Women's satisfactionwith Maternal Health Care: A Review of Literature from developing Countries. Bmc Pregnancy and Childbirth. 15(1), 97.https://doi.org/10.1186/s12884-015-0525-0.

[40] Stevens N. (2011): Perceived Control and Maternal Satisfaction with the Childbirth experience. Published Doctor Theses of Philosophy. The Graduate Faculty of the University of Kansas, Us. April 7, 2011.

[41] Tarin, T., Feifer, A., Kimm, S., Chen, L., Sjoberg, D., Coleman, J., \& Russo, P. (2014): Impact of a Common clinical Pathway on Length of Hospital Stay in Patients Undergoing Open and minimally Invasive Kidney Surgery. The Journal of Urology.191 (5), 12251230.https://doi.org/10.1016/j.juro.2013.11.030.

[42] Thiele R., Rea K., Turrentine F., Friel C., Hassinger T., Goudreau B. \&Mcmurry T. (2015):Standardizationof care: Impact Of An Enhanced Recovery Protocol On Length Of Stay, Complications, and direct Costs After Colorectal Surgery. Journal of the American College of surgeons, 220(4), 430-443.https://doi.org/10.1016/j.jamcollsurg.2014.12.042.

[43] Varghese J, Rajagopal K. (2013): Development of a New Tool for Evaluating Postnatal Mother's satisfaction Following Nursing Care: In India. Journal of Biology, Agriculture and healthcare. 2(5):7-19

[44] World Health Organization (2018): Delivering Quality Health Services: A Global Imperative for universal Health Coverage.

[45] Younas A., \&Sundus A. (2018,): Patients' Experiences And Satisfaction About Care Provided Bymale Nurses In Medical Surgical Units In Islamabad, Pakistan: A Pilot Study. In Nursing Forum. 53 (1): 12-19.https://doi.org/10.1111/nuf.12212.

[46] Yuenyong S., Obrien B. \&Jitapeet V. (2012): Effects of Labor Support Form Close Female Relative on labor and Maternal Satisfaction in A Thai Setting. Jognn 2012; 41(1):45-56.https://doi.org/10.1111/j.1552-6909.2011.01311.x. 